\title{
Early pregnancy diagnosis on days 18 to 21 postinsemination using high-resolution imaging in lactating dairy cows
}

\author{
S. Scully, ${ }^{*}$ S. T. Butler,† A. K. Kelly, $\ddagger$ A. C.O. Evans, $\ddagger$ P. Lonergan, $\ddagger$ and M. A. Crowe ${ }^{\star 1}$ \\ *School of Veterinary Medicine, University College Dublin, Belfield, Dublin 4, Ireland \\ †Dairy Production Research Centre, Teagasc, Moorepark, Fermoy, Co. Cork, Ireland \\ $\ddagger$ School of Agriculture and Food Science, University College Dublin, Belfield, Dublin 4, Ireland
}

\section{ABSTRACT}

The aim was to assess the ability of corpus luteum (CL) and uterine ultrasound characteristics on $\mathrm{d} 18$ to 21 to predict pregnancy status in lactating dairy cows. Ultrasound examinations were carried out on cows (n $=164$ ) on $\mathrm{d} 18$ to 21 following artificial insemination (AI). Images of the uterus and CL were captured using a Voluson $i$ ultrasound device (General Electric Healthcare Systems, Vienna, Austria) equipped with a $12-\mathrm{MHz}$, multi frequency, linear array probe. Serum concentrations of progesterone were determined from blood samples collected at each ultrasound examination. Images of the CL were captured and stored for calculation of CL tissue area and echotexture. Images of the CL and associated blood flow area were captured and stored for analysis of luteal blood flow ratio. Longitudinal B-mode images of the uterine horns were stored for analysis of echotexture. Diagnosis of pregnancy was made at each ultrasound examination based on CL blood flow, CL size, and uterine echotexture. Pregnancy was confirmed by ultrasonography on d 30 after AI. The relationship between ultrasound measures and pregnancy outcome, as well as the accuracy of the pregnancy diagnosis made at each ultrasound examination was assessed. Progesterone concentrations and CL tissue area were greater in pregnant compared with nonpregnant cows on all days. The CL blood flow ratio was higher in pregnant compared with nonpregnant cows on d 20 and 21 after AI. Echotexture measures of the CL and uterus were not different between pregnant and nonpregnant cows on any day of examination. The best logistic regression model to predict pregnancy included scores for CL blood flow, CL size, and uterine echotexture on d 21 following AI. Accuracy of pregnancy diagnosis was highest on d 21, with sensitivity and specificity being 97.6 and $97.5 \%$, respectively. Uterine echotexture scores were similar for pregnant and nonpregnant cows from d 18 to 20 . On d 21, pregnant cows had higher uterine echotexture scores

Received September 23, 2013.

Accepted January 21, 2014.

${ }^{1}$ Corresponding author: mark.crowe@ucd.ie compared with nonpregnant cows. The logistic regression equation most likely to provide a correct pregnancy diagnosis in lactating dairy cows included the visual score for CL blood flow, CL size, and uterine echotexture on d 21 after AI. In support of this finding, the diagnostic accuracy for visual scores of CL blood flow, CL size, and uterine echotexture were also highest on d 21.

Key words: uterus, corpus luteum, ultrasound, dairy cow, early pregnancy

\section{INTRODUCTION}

Pregnancy diagnosis is a routine tool used in the reproductive management of dairy cows (Fricke, 2002) to identify both pregnant and nonpregnant cows (Pierson and Ginther, 1984; Kastelic et al., 1988). Since the 1950 s, fertility in dairy cows has declined in association with intensive selection for increased milk production (Butler, 2003). Within the same timeframe, a decline in the duration and intensity of estrous activity has been observed (Lopez et al., 2004; Dobson et al., 2008). The result is poor estrous detection and higher culling rates (Stevenson et al., 2003). Currently, the average estrous detection rates in Ireland are approximately $70 \%$ (Mee, 2004; Dillon et al., 2006). Furthermore, the rate of early embryo loss in both moderate- and high-yielding dairy cows is estimated to be between 40 and $56 \%$, respectively (Diskin and Morris, 2008). Over half of this loss is estimated to occur before d 16 after breeding (Dunne et al., 2000; Diskin and Morris, 2008), with some research suggesting greater loss occurring before d 8 in high-yielding cows (Sartori et al., 2010).

It is important that all eligible cows are inseminated soon after the end of the voluntary waiting period to maintain reproductive efficiency (Dewey et al., 2010). The early identification of nonpregnant cows has the potential to have a direct effect on the calving to conception interval (Stevenson et al., 2003). Furthermore, a high cost benefit has been associated with early pregnancy detection of dairy cows (Oltenacu et al., 1990). Blood tests are now available for pregnancy diagnosis through the detection of pregnancy-associated glycoproteins (Silva et al., 2007); however, the test has a 2-d 
wait period and requires cows to be approximately 25 to $30 \mathrm{~d}$ postinsemination for accurate results (Green et al., 2005, 2009). Rapid pregnancy-associated glycoproteins tests have revealed a high degree of accuracy in both cows and heifers that are at least $25 \mathrm{~d}$ post-AI (Silva et al., 2007; Green et al., 2009).

The process of pregnancy recognition and implantation involves major remodeling of the endometrium, in particular the endometrial glands (Gray et al., 2001; Spencer et al., 2007). Ultrasound may have the ability to monitor several uterine characteristics associated with increased endometrial glandular secretions, including the presence of edema (Gajewski et al., 1999) and intrauterine fluid (Pierson and Ginther, 1987; Kastelic et al., 1991). Ultrasound examinations of the uterus have noted a change in the amount of uterine fluid, along with the number of grey zones just before ovulation in cattle (Pierson and Ginther, 1987). Furthermore, changes in uterine echotexture from d 18 to 21 have been noted in cyclic animals (Kastelic et al., 1989).

Most commercial ultrasound machines operate between 5 and $7.5 \mathrm{MHz}$. Studies have not used probes more powerful than $7.5 \mathrm{MHz}$ since research first began on the use of ultrasound for pregnancy diagnosis in commercial dairy herds (Kastelic et al., 1989, 1991; Pieterse et al., 1990; Romano et al., 2006). Ultrasound characteristics of the uterus and corpus luteum (CL) have been assessed as possible markers for early pregnancy diagnosis. In isolation, these markers do not appear to perform well (Kastelic et al., 1989; Badtram et al., 1991; Herzog et al., 2011). In practice, pregnancy diagnosis involves examination of the entire reproductive tract. Even when an embryonic heartbeat is detected, it is recommended that the ovaries be assessed for presence of a CL (López-Gatius and García-Ispierto, 2010).

The overall aim of the current study was to assess the ability of ultrasound measures of CL and uterine characteristics from d 18 to 21 following AI in dairy cows to predict pregnancy status. Specifically, we addressed questions of (1) whether changes in uterine and CL characteristics from d 18 to 21 were different in pregnant and nonpregnant dairy cows; (2) if image analysis data could predict pregnancy status in dairy cows using logistic regression; and (3) how accurate pregnancy can be predicted by a visual diagnosis using scores for CL size, CL blood flow, and uterine echotexture for pregnancy diagnosis.

\section{MATERIALS AND METHODS}

\section{Animals and Treatments}

All experimental procedures involving animals were licensed by the Department of Health and Children,
Ireland. Protocols were in accord with the Cruelty to Animals Act (Ireland 1876) and the European Community Directive 86/609/EC and were sanctioned by the Institutional Animal Research Ethics Committee in University College Dublin.

Dairy cows $(n=164)$ of varying age, stage of lactation, and parity were AI following detected estrus. A total of 344 ultrasound examinations were carried out from d 18 to 21. Ultrasound examinations were carried out during one autumn (November to December 2012, $\mathrm{n}=22$ cows scanned) and one spring (May to June $2012, n=142$ cows scanned) breeding season. Jersey, Holstein-Jersey, and Holstein-Friesian cows were used. All cows were milked twice daily (0700 and $1600 \mathrm{~h}$ ).

Cows in the autumn-calving group were housed indoors in a cubicle house with slatted passageways for the duration of the experiment. Cows were offered a diet that consisted of 50:50 maize silage $(\mathrm{DM}=344$ $\mathrm{g} / \mathrm{kg}, \mathrm{CP}=76 \mathrm{~g} / \mathrm{kg}$, and $\mathrm{ME}=11.8 \mathrm{MJ} / \mathrm{kg}$ of $\mathrm{DM})$, grass silage $(\mathrm{DM}=239 \mathrm{~g} / \mathrm{kg}, \mathrm{CP}=101 \mathrm{~g} / \mathrm{kg}$, and $\mathrm{ME}$ $=11.1 \mathrm{MJ} / \mathrm{kg}$ of DM) ad libitum, plus $8 \mathrm{~kg}$ of concentrates $(\mathrm{DM}=883 \mathrm{~g} / \mathrm{kg}, \mathrm{CP}=281 \mathrm{~g} / \mathrm{kg}$, and $\mathrm{ME}$ $=12.9 \mathrm{MJ} / \mathrm{kg}$ of $\mathrm{DM}$ ) per day at milking. Cow in the spring-calving group were fed a pasture-based diet with a daily DM allowance of $14 \mathrm{~kg}$ supplemented with $8 \mathrm{~kg}$ of concentrate per day at milking.

\section{$B W$ and $B C S$}

Body weight and BCS were recorded weekly. Body condition score was assessed by the same person on a scale of 1 to 5 (with 1 being extremely thin and 5 being extremely fat) with increments of 0.25 (Lowman et al., 1976). The mean \pm SEM weights of cows in the pregnant and nonpregnant groups were $521.97 \pm 11.39$ and $517.42 \pm 11.05 \mathrm{~kg}(P=0.77)$, respectively. The mean \pm SEM BCS of cows in the pregnant and nonpregnant groups were $2.76 \pm 2.6$ and $2.77 \pm 2.75(P=0.79)$, respectively.

\section{Progesterone Assay}

Blood samples were collected by coccygeal venipuncture into Vacutainers (Becton Dickinson, Plymouth, UK) at each ultrasound examination for assay of progesterone (P4) concentrations. Following collection, blood samples were refrigerated $\left(4^{\circ} \mathrm{C}\right)$ for 12 to $24 \mathrm{~h}$ before being centrifuged at 1,500 $\times g$ for $20 \mathrm{~min}$ at $4^{\circ} \mathrm{C}$. Concentrations of $\mathrm{P} 4$ were measured using a commercially available solid-phase RIA (Coat-A-Count Progesterone, Diagnostic Products Corp., Los Angeles, CA) as previously described and validated (Forde et al., 2011). Intraassay CV were 12.6, 5.8, and $8.0 \%$ for serum pools containing low, medium, and high P4 
concentrations, respectively. The interassay CV for the same quality control serum pools were 5.2, 24.5, and 6.9 , respectively.

\section{Ultrasound Examinations}

All ultrasound (US) observations were conducted by the same operator using a Voluson $i$ ultrasound device (General Electric Healthcare Systems, Vienna, Austria) equipped with a 12L RNA linear array, multifrequency transducer operating between 4 and $12 \mathrm{MHz}$. Ultrasound machine settings (depth, echo-amplification, persistence, output power, and so on) remained the same for all US examinations. Examinations were carried out on d 18 to 21 following AI. Due to logistics, the same animal was not always scanned on all $4 \mathrm{~d}$ of US examination. Cows were examined at the same time every day (between 0700 and $0900 \mathrm{~h}$ ) following the morning milking.

\section{US of the $C L$}

Three cross-sectional images of the maximal area of the CL were recorded. The CL tissue area $\left(\mathrm{cm}^{2}\right)$ was calculated using PixelFlux (Version 1.0, Charmeleon software, Leipzig, Germany) and was corrected for the area of a cavity, where present. The mean of the 3 cross-sectional images was calculated and used for statistical analysis.

\section{Doppler Blood Flow Image Analysis}

Power flow Doppler was used for blood flow mapping of the CL. Fixed, default power Doppler system controls were used to exclude any variations in recording. Settings for power Doppler examinations were depth $=$ $3.5 \mathrm{~cm}$, power $=87 \%$, pulse repetition frequency $=0.9$ $\mathrm{kHz}$, and gain $=1.0$. Three power Doppler images were recorded at both the maximum CL area and vascular transverse section. Care was taken to ensure that the entire CL was located within the Doppler sample box. PixelFlux software was used to quantify the area per centimeter-squared of color pixels within the CL (CL blood flow area). Mean CL blood flow area was calculated from 3 single images for statistical analysis. In addition, the ratio of CL blood flow area to total CL tissue area was calculated.

To validate the repeatability of CL blood flow measures, beef heifers $(n=5)$ were each scanned 5 times within a period of $1 \mathrm{~h}$, and images of CL blood flow were captured at each US exam. Repeatability estimates for CL vascularity revealed that CL blood flow area had a repeatability of 0.35 with a variance of 0.0089 . The
CL blood flow ratio had a repeatability of 0.25 with a variance of 0.07 .

\section{US of the Uterus}

Three longitudinal images of both uterine horns were recorded using two-dimensional B-mode US. As with the CL measurements, fixed preinstalled B-mode controls were used. Measurements of 3 images of both uterine horns were taken for gray scale analysis.

\section{Uterine and CL Grayscale Image Analysis}

Analysis of echotexture was carried out using a computer program specifically designed for US image analysis (MaZda v4.6, Technical University of Lodz, Institute of Electronics, Poland; Szczypiński et al., 2009; Strzelecki et al., 2013). When analyzing uterine image characteristics, separate means were calculated for ipsilateral and contralateral uterine horns. Digitized images of the longitudinal sections of the uterine horns were divided into 4 equal quadrants. In each of these quadrants, a circular region of interest (ROI) with a size of at least 1,000 pixels was placed on the image. The ROI was restricted to the endometrial tissue, avoiding myometrial tissue and intrauterine fluid. The echotexture parameters used were angular second moment (homogeneity) and contrast as described by (Raeth et al., 1985). The mean value of the ROI of the echotexture parameters was used for further analysis.

In the case of the CL echotexture analysis, 3 images of the CL were examined. The CL was divided into 4 equal quadrants. A circular region was identified in each quadrant; the homogeneity and contrast were calculated as described for uterine echotexture analysis. The mean of the 3 images was used for final statistical analysis.

For quantification of the echotexture parameters, pixel pairs were assigned to each other on the basis of a specific, predefined placement vector, creating a two-dimensional frequency histogram characterizing the occurrence of individual pixel pairs. This is known as the co-occurrence matrix, and from it measures of homogeneity and contrast are statistically calculated. Contrast is a measure of the image texture smoothness and describes gray level variations. Angular second moment (homogeneity) is a measure of uniformity. Contrast was higher when more gray scale variations were present within the region of interest. The formula for contrast and homogeneity area is

$$
\text { Homogeneity }=\sum_{i-1}^{N} \sum_{j-1}^{N} P^{2}(i, j) \text { and }
$$


Score

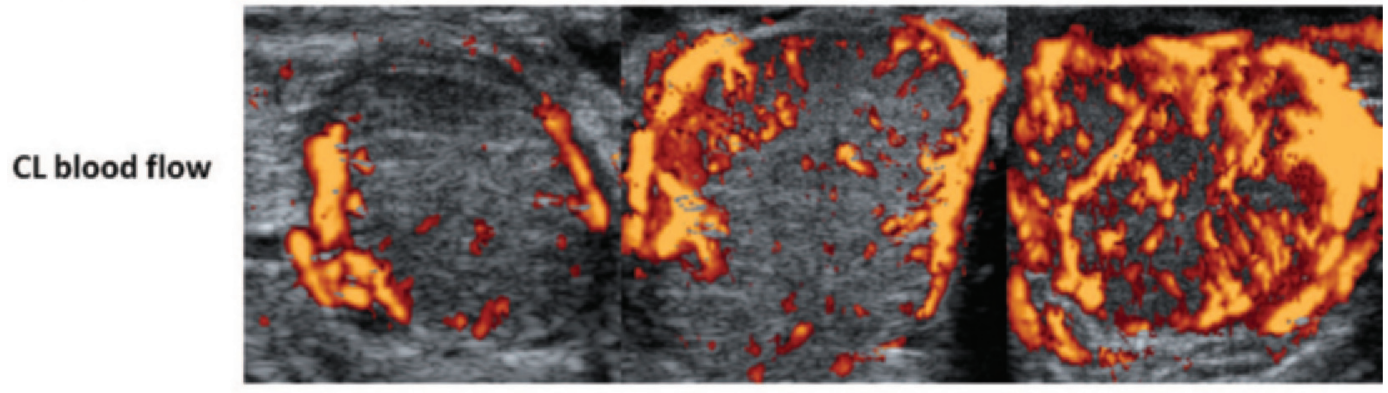

Score

1

2

3

Uterine
echo-
texture

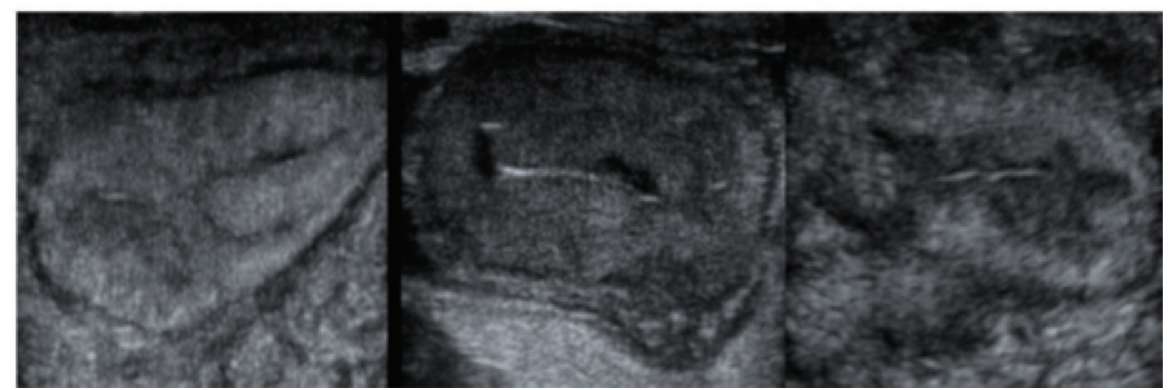

Figure 1. Image characteristics of visual scores for (top) corpus luteum (CL) blood flow and (bottom) uterine echotexture (1-3). Scores were incorporated into the model to best predict pregnancy outcome following an ultrasound exam on d 30. The scores were also used for diagnosis of pregnancy on d 18 to 21 after AI.

$$
\text { Contrast }=\sum_{i-1}^{N} \sum_{j-1}^{N}(i-j)^{2} \cdot P(i, j)
$$

where $N=$ number of gray levels; $i$ and $j=$ neighboring pixel intensities; and $P(i, j)=$ frequency of the co-occurrence.

\section{Visual Scores}

During each US examination between d 18 and 21 post-AI, images of CL size, uterine echotexture, and CL vascularity were visually scored. Images describing CL blood flow and uterine echotexture are presented in Figure 1. Blood flow to the CL was scored on a scale of 1 to 3 ( 1 = low or no blood flow, low intensity; $2=$ intermediate blood flow and intensity; and $3=$ maximum blood flow and intensity). The CL size was estimated using the scale on the US monitor and scored on a scale of 1 to 3 ( $1=\leq 10-15 \mathrm{~mm} ; 2=15.1-20 \mathrm{~mm}$; and $3=>20 \mathrm{~mm})$. Uterine echotexture was scored from 1 to 3 ( $1=$ even texture, no nonechogenic spots; $2=$ intermediate amounts of nonechogenic spots along the endometrium; and $3=$ maximum amounts of nonechogenic spots on the endometrium). A final pregnancy diagnosis was made on d 30 (US exam 2) post-AI by an independent operator. Cows were retrospectively assigned as either pregnant or not pregnant based on the presence of an embryonic heartbeat.
The accuracy of pregnancy diagnosis was calculated from the comparison of the outcome of US exam 1 with US exam 2. The sensitivity was defined as the ability of the first ultrasonography (US exam 1) to correctly detect pregnancy among cows pregnant at the final ultrasound exam (US exam 2). Specificity was defined as the ability of US exam 1 to correctly identify nonpregnant cows based on nonpregnancy diagnosis at US exam 2 . Positive predictive value (PPV) was the probability of a cow diagnosed as pregnant at US exam 1 and also diagnosed pregnant on US exam 2. Negative predictive value (NPV) was the probability of cows diagnosed as nonpregnant at US exam 1 and also diagnosed as nonpregnant at US exam 2.

The formulas used to calculate each measure of accuracy were

$$
\begin{gathered}
\text { Sensitivity }=a /(a+d), \\
\text { Specificity }=b /(b+c), \\
\operatorname{PPV}=a /(a+c), \text { and } \\
\operatorname{NPV}=b /(b+d),
\end{gathered}
$$

where $a=$ cow diagnosed as pregnant at US exam 1 and subsequently diagnosed as pregnant at US exam 2; $b=$ cow diagnosed as nonpregnant at US exam 1 and 
subsequently diagnosed as nonpregnant at US exam $2 ; c=$ cow diagnosed as pregnant at US exam 1 and subsequently diagnosed as not pregnant at US exam 2 (i.e., false positive); $d=$ cow diagnosed as not pregnant at US exam 1 and subsequently diagnosed as pregnant at US exam 2 (i.e., false negative).

\section{Statistical Analyses}

Cow was the experimental unit throughout the experiment. The data were checked for normality and homogeneity by histograms, qqplots, and formal statistical tests using the UNIVARIATE procedure of SAS (version 9.3; SAS Institute Inc., Cary, NC). Data that were not normally distributed were transformed by raising the variable to the power of lambda. The appropriate lambda value was obtained by conducting a Box Cox transformation analysis using the TRANSREG procedure of SAS. The transformed values were used to calculate the $P$-values. The corresponding estimated marginal means and standard errors of the nontransformed data are presented in the results for clarity. Ultrasound measurements, echotexture analysis measures, and $\mathrm{P} 4$ were analyzed using mixed models with repeated measures from d 18 to 21 . Fixed effects included experimental treatment (pregnant, not pregnant), day, season, and their interactions. The interaction term was excluded from the final model if it was not statistically significant $(P>0.05)$. Cow within treatment was included as a random effect. The type of variancecovariance structure used was chosen depending on the magnitude of the Akaike information criterion and the Bayesian information criterion from models run under compound symmetry, unstructured, autoregressive, or Toeplitz variance-covariance structures. The frequency of scored data and the percentage of the population obtaining all possible score combinations were calculated. Logistic regression analysis was used to evaluate the relationship between ultrasound measures on $\mathrm{d} 18$ to 21 and pregnancy outcome. The PDIFF command incorporating the Tukey test was applied to evaluate pairwise comparisons between treatment means. Stepwise regression analysis was used to evaluate the relationship between the dependent variable pregnancy outcome and independent variables generated from the ultrasound measurements and plasma $\mathrm{P} 4$ analysis. The terms included in the logistic regression model were P4, CL tissue area, CL blood flow area, CL blood flow ratio, CL contrast, CL homogeneity, uterine contrast, uterine homogeneity, CL blood flow score, CL size score, and uterine echotexture score. The reference test for diagnostic accuracy of visual scores was detection of an embryonic heartbeat on d 30 after AI. Sensitivity, specificity, PPV, and NPV were calculated using PROC FREQ. The distribution of scores in pregnant and nonpregnant cows at each US exam was calculated. Based on this distribution, a cut-off value was tested when the scores for CL blood flow, CL size, and uterine echotexture were combined. Test for the significance of accuracy measures were done using the Chi-squared statistic.

\section{RESULTS}

\section{Animals and Treatments}

Following a definitive pregnancy diagnosis on d 30, cows were retrospectively allocated into 1 of 2 groups, pregnant or not pregnant. The number and relative percentage of cows diagnosed into each of these groups on each day of ultrasound examination are described in Table 1.

\section{P4}

Progesterone concentrations were significantly greater in pregnant than nonpregnant cows on all days of US examination $(P<0.0001$; Figure 2a) and were unaffected by day $(P=0.18)$ or season $(P=0.4)$. No interactions between pregnancy status and the other fixed effects $(P=0.2)$ were observed. Concentrations of $\mathrm{P} 4$ in milk of the pregnant and nonpregnant cows on $\mathrm{d}$ 21 were $7.45 \pm 0.45$ and $1.8 \pm 0.45 \mathrm{ng} / \mathrm{mL}$, respectively. On d 21, 36 of the 93 cows examined had P4 $<1 \mathrm{ng} /$ $\mathrm{mL}$, whereas 16 cows had $\mathrm{P} 4>1 \mathrm{ng} / \mathrm{mL}$ following the final confirmation of pregnancy status on d 30. Distributions of values for $\mathrm{P} 4$ in pregnant and nonpregnant cows on d 21 following AI are presented in Figure 3b.

Table 1. Summary of numbers of confirmed pregnant and nonpregnant cows for each day of ultrasound examination following a final pregnancy diagnosis on d 30 following AI

\begin{tabular}{lccccc}
\hline & \multicolumn{3}{c}{ Day of ultrasound examination } & \\
\cline { 2 - 5 } Item $(\mathrm{n})$ & $\mathrm{d} 18$ & $\mathrm{~d} 19$ & $\mathrm{~d} 20$ & $\mathrm{~d} 21$ & Total \\
\hline Total cows & 80 & 80 & 90 & 94 & 344 \\
Total pregnant & 44 & 44 & 43 & 42 & 173 \\
Total nonpregnant & 36 & 36 & 47 & 52 & 171 \\
\hline
\end{tabular}



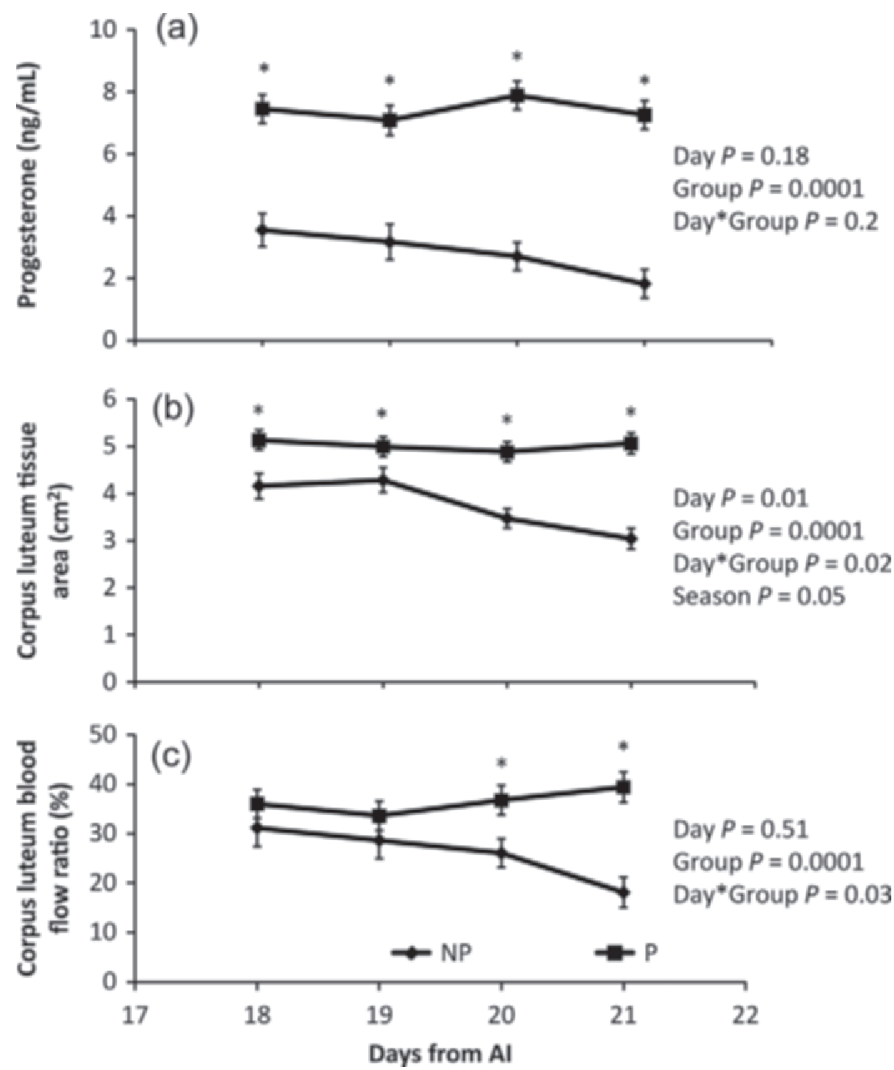

Figure 2. Characterization of progesterone (a), corpus luteum tissue area (b), and corpus luteum blood flow ratio (c) in pregnant $(\mathrm{P}$; $\mathrm{n}=173 ; \mathbf{\square})$ and nonpregnant $(\mathrm{NP} ; \mathrm{n}=171 ;$ ) cows from d 18 to 21 after AI.

\section{Tissue Area}

Tissue area values for the CL in pregnant and nonpregnant cows from d 18 to 21 are summarized in Figure $2 \mathrm{~b}$. The CL tissue area was affected by pregnancy status $(P<0.001)$, day $(P=0.01)$, season $(P=0.05)$, and the interaction between pregnancy status and day $(P=0.02)$. Pregnant cows had greater $(P=0.0001)$ CL tissue area than nonpregnant cows from d 18 to 21. No change in CL tissue area was observed for pregnant cows from d 18 to $21(P=0.9)$, whereas CL tissue area declined $(P=0.0006)$ in nonpregnant cows in the same period.

\section{Blood Flow Area and Blood Flow Ratio}

Significant effects of pregnancy status $(P<0.001)$ and the interaction between pregnancy status and day $(P<0.05)$ on CL blood flow area and blood flow ratio were observed. The effects of day $(P>0.5)$ and season $(P>0.05)$ were not significant. Blood flow area was greater in pregnant than in nonpregnant cows $(P<$ 0.0001 ) from d 18 to 21 . Pregnant and nonpregnant cows had similar values for CL blood flow ratio on $\mathrm{d} 18$ and 19. On d 21, pregnant cows had significantly higher $(P=0.0001)$ CL blood flow ratios than nonpregnant cows. Distribution of values for CL blood flow ratios in pregnant and nonpregnant cows on d 21 following AI are presented in Figure 3a.

\section{Echotexture}

Values for contrast of the CL in pregnant and nonpregnant cows are summarized in Figure 4a. A significant season effect $(P=0.001)$ was observed, with the

(a)

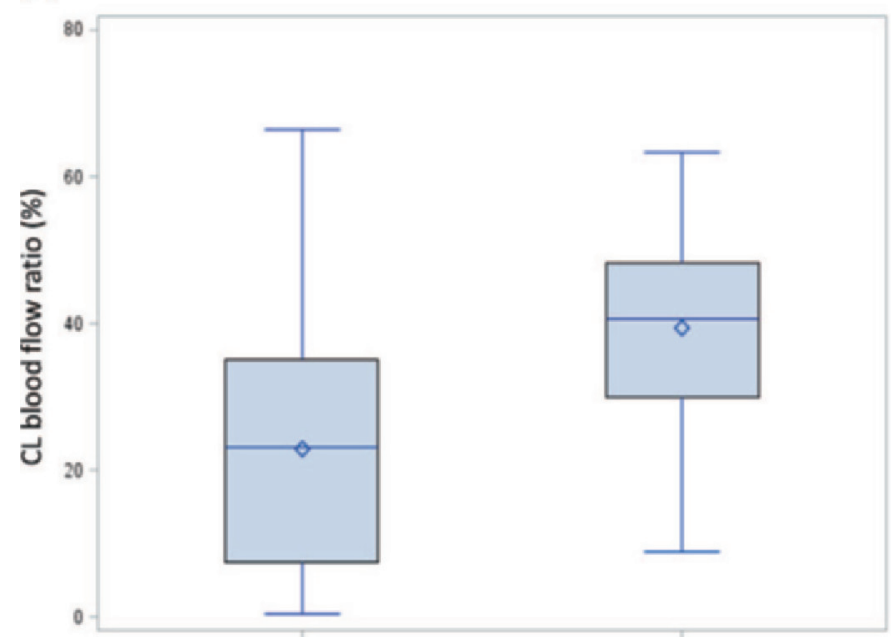

(b)

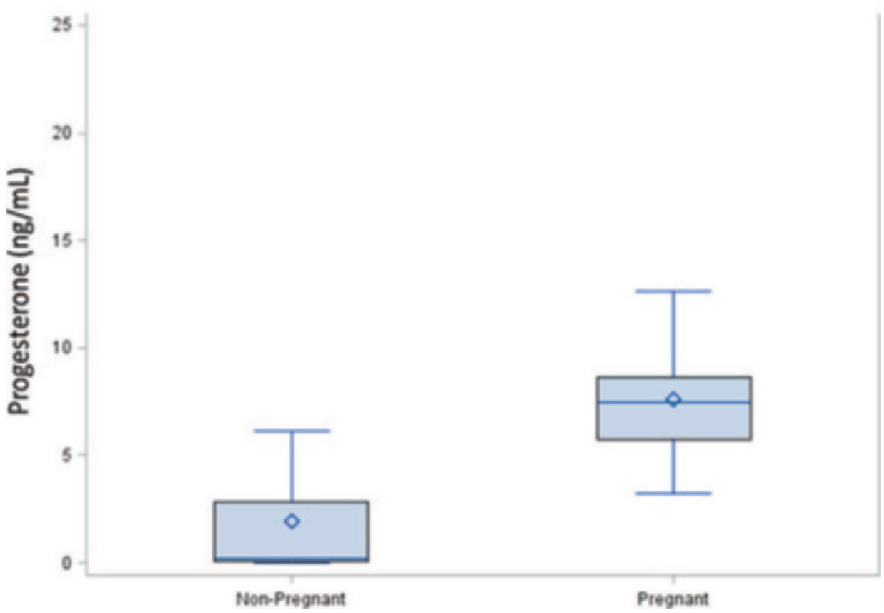

Figure 3. Distribution of values for (a) corpus luteum (CL) blood flow area and (b) progesterone in pregnant and nonpregnant cows on $\mathrm{d}$ 21 following AI represented by box and whisker plots that include the median of all values (represented by the horizontal line inside the box), the interquartile range (represented by the ends of the box), and the highest and lowest observations (represented by vertical lines running through the box). Color version available in the online PDF. 

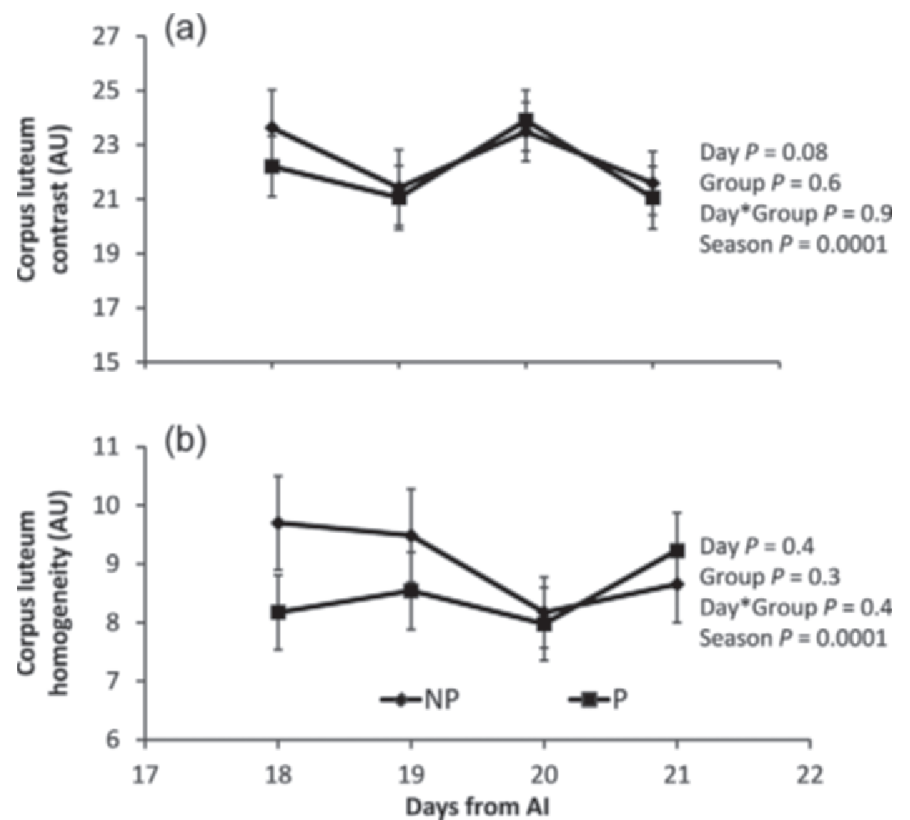

Figure 4. Corpus luteum contrast (a) and corpus luteum homogeneity (b) in pregnant $(\mathrm{P} ; \mathrm{n}=173 ; \mathbf{\square})$ and nonpregnant dairy cows $(\mathrm{NP} ; \mathrm{n}=171 ; \diamond)$ from d 18 to 21 after AI.

effect of day $(P=0.08)$ tending to be significant. No effect of pregnancy status $(P=0.6)$ or interaction between pregnancy status and day $(P=0.9)$ was noted for CL contrast.

Values for homogeneity of the CL in pregnant and nonpregnant cows are summarized in Figure 3b. No effects of day $(P=0.4)$, pregnancy status $(P=0.3)$, or the interaction between pregnancy and day $(P=$ $0.4)$ were observed. A significant effect of season $(P=$ $0.0001)$ was noted. Values for CL homogeneity were not different between pregnant and nonpregnant cows from d 18 to 21 .

\section{Uterine Echotexture}

Values for uterine contrast in pregnant and nonpregnant cows from d 18 to 21 are summarized in Figure 5a. Significant day $(P=0.002)$ and season effects $(P$ $=0.0001)$ were present. However, no significant effect of pregnancy status $(P=0.8)$ or interaction between pregnancy status and day $(P=0.3)$ was noted. No significant differences were observed in uterine contrast in pregnant compared with nonpregnant cows from $\mathrm{d}$ 18 to 21.

Values for uterine homogeneity in pregnant and nonpregnant cows from d 18 to 21 are summarized in Figure 5b. We observed no effects of day $(P=0.3)$, pregnancy status $(P=0.9)$, or interaction of pregnancy status and day $(P=0.3)$. A significant effect of season
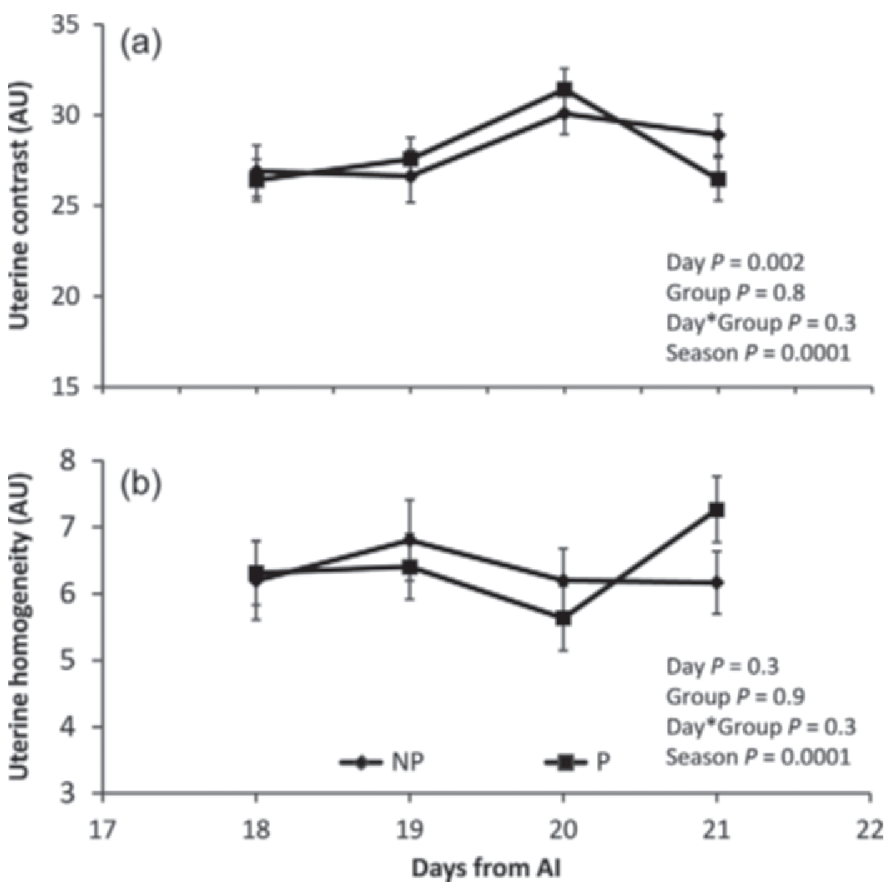

Figure 5. Uterine contrast (a) and uterine homogeneity (b) in pregnant $(\mathrm{P} ; \mathrm{n}=173 ; \mathbf{\square})$ and nonpregnant $(\mathrm{NP} ; \mathrm{n}=171 ; \diamond)$ dairy cows from d 18 to 21 after AI.

$(P=0.0001)$ was noted. No significant differences in uterine homogeneity were present between pregnant and nonpregnant cows on d 18 to 21 .

\section{Logistic Regression Analysis}

Prediction equations from d 18 to 21 are presented in Table 2 (see also Supplementary Table S1; http:// dx.doi.org/10.3168/jds.2013-7518). Progesterone had the highest predictive score from d 18 to 21 following $\mathrm{AI}$, with the $\mathrm{R}^{2}$ value increasing from 0.35 on $\mathrm{d} 18$ to 0.57 on $\mathrm{d} 21$. Individually, the visual scores for CL size, CL blood flow, and uterine echotexture all had significant $\mathrm{R}^{2}$ values. However, the $\mathrm{R}^{2}$ value was always higher on d 18 to 21 when the visual scores were combined to create one single score. This combined score increased from 0.13 on d 18 to 0.73 on d 21 . This value was always higher when compared with scores where 2 score variables were used (e.g., CL blood flow and CL size combined).

Results for the stepwise logistic regression are presented in Table 3 (see also Supplementary Table S2). The combined score of CL size, CL blood flow, and uterine echotexture was the most consistently significant contributor to the best predictive model for pregnancy status appearing on all days of US examination. The logistic regression model with the highest $\mathrm{R}^{2}, 0.72$, occurred on d 21. 


\section{Visual Scores}

The frequency distribution of visual scores for CL blood flow, CL size, and uterine echotexture are summarized in Figure 6. Cows that were confirmed pregnant had a higher frequency for scores of 3 for CL blood flow and CL size, indicative of more CL blood flow and larger CL diameter; whereas nonpregnant cows had a higher frequency of low scores for CL blood flow and CL size, suggestive of less blood flow and smaller CL diameter. The distribution of the frequency of scores for uterine echotexture was similar for both pregnant and nonpregnant cows.

\section{Assigning a Pregnancy Diagnosis Using Visual Scores}

The scores for CL blood flow, CL size, and uterine echotexture were added together such that the pregnancy diagnosis was based on a total score, where the minimum score achievable was 3 and the maximum was 9. Diagnostic accuracy was also tested when one score category was removed (see Supplementary Table S3; http://dx.doi.org/10.3168/jds.2013-7518). The optimum cut-off was determined by testing the diagnostic accuracy of all possible combinations of scores and cut-offs when the 3 score categories were included (see Supplementary Tables S3 and S4).

Highest diagnostic accuracy was achieved when all 3 scored variables (CL blood flow, CL size, and uterine echotexture) were included and when the diagnostic accuracy cut-off of 3 to 5 was assigned to indicate nonpregnancy, whereas scores from 7 to 9 inclusive were indicative of a pregnant animal. The frequency distribution of the combined scores among pregnant and nonpregnant were calculated and revealed that the $63 \%$ of nonpregnant cows scored between 3 and 5, whereas $83 \%$ of pregnant cows had scores of 7 to 9 . Both groups had a similar frequency, $7 \%$, for scores of 6 .

Results obtained for the pregnancy diagnosis of cows using the optimum cut-offs and when visual scores for CL blood flow, CL size, and uterine echotexture were used to make the pregnancy diagnosis are described in Table 4. As animals that received a score of 6 were removed from the analysis, this table is representative of approximately $93 \%$ of all animals scanned throughout the study period. Sensitivity increased from 78.9 to $97.6 \%$ on d 18 and 21 after AI, respectively $(P<$ $0.0001)$. During the same interval, specificity increased from 70.3 to $97.5 \%(P<0.0001)$. The positive predictive value increased from 66.7 and $78.8 \%(P<0.0001)$ throughout the examination period. The negative predictive value increased from $70.3 \%$ on d 18 to $97.5 \%$ on d $21(P<0.0001)$. The maximum sensitivity, specific- ity, PPV, and NPV values were all obtained on d 21 ( $P$ $<0.0001)$.

As the combined scores were made up of various combinations of the individual scores for CL blood flow, CL size, and uterine echotexture, the frequency of all possible score combinations were calculated. The score combinations that contributed most to the diagnosis of either pregnant or nonpregnant cows are summarized in Table 5 .

\section{Correlation}

A positive correlation was found between visual scores and P4 concentrations (Table 6). A significant $(P<0.0001)$ moderate correlation was observed between progesterone and the visual scores of CL size and CL blood flow ( $\mathrm{r}=0.62$ and $\mathrm{r}=0.6$, respectively). Low correlation was found between $\mathrm{P} 4$ and the visual score for uterine echotexture $(\mathrm{r}=0.17 ; P<0.05)$. The correlations between progesterone and CL size for nonpregnant cows was $\mathrm{r}=0.83(P<0.001)$. No correlation was observed between $\mathrm{P} 4$ concentrations and CL size for pregnant cows $\mathrm{r}=-0.16(P=0.32)$.

\section{DISCUSSION}

The period from d 18 to 21 after AI can represent 1 of 2 biological extremes in cattle. In the event of successful maternal recognition of pregnancy, it represents the beginning of placental attachment. Alternatively, where maternal recognition is not achieved (due to fertilization failure, a poor uterine environment, or early embryo mortality), a return to cyclicity ensues. The main findings from the present study were:

1. pregnant cows had significantly higher P4 and CL tissue area compared with nonpregnant cows from d 18 to 21 after AI;

2. pregnant cows had higher CL blood flow ratio compared with nonpregnant cows on d 20 and 21 after AI;

3. no differences were observed between pregnant and nonpregnant cows from d 18 to 21 for uterine and CL echotexture measurements;

4. the logistic regression equation most likely to provide a correct pregnancy diagnosis included the visual score for CL blood flow, CL size, and uterine echotexture on d 21 after AI; and

5. when the visual scores were used during US examination, pregnancy diagnostic PPV and NPV were 79 and $97 \%$, respectively, on d 21.

Progesterone is an important contributing factor toward early embryo survival (Morris and Diskin, 
Table 2. Logistic regression model for predictors of pregnancy from d 18 to 21 after AI in lactating dairy cows

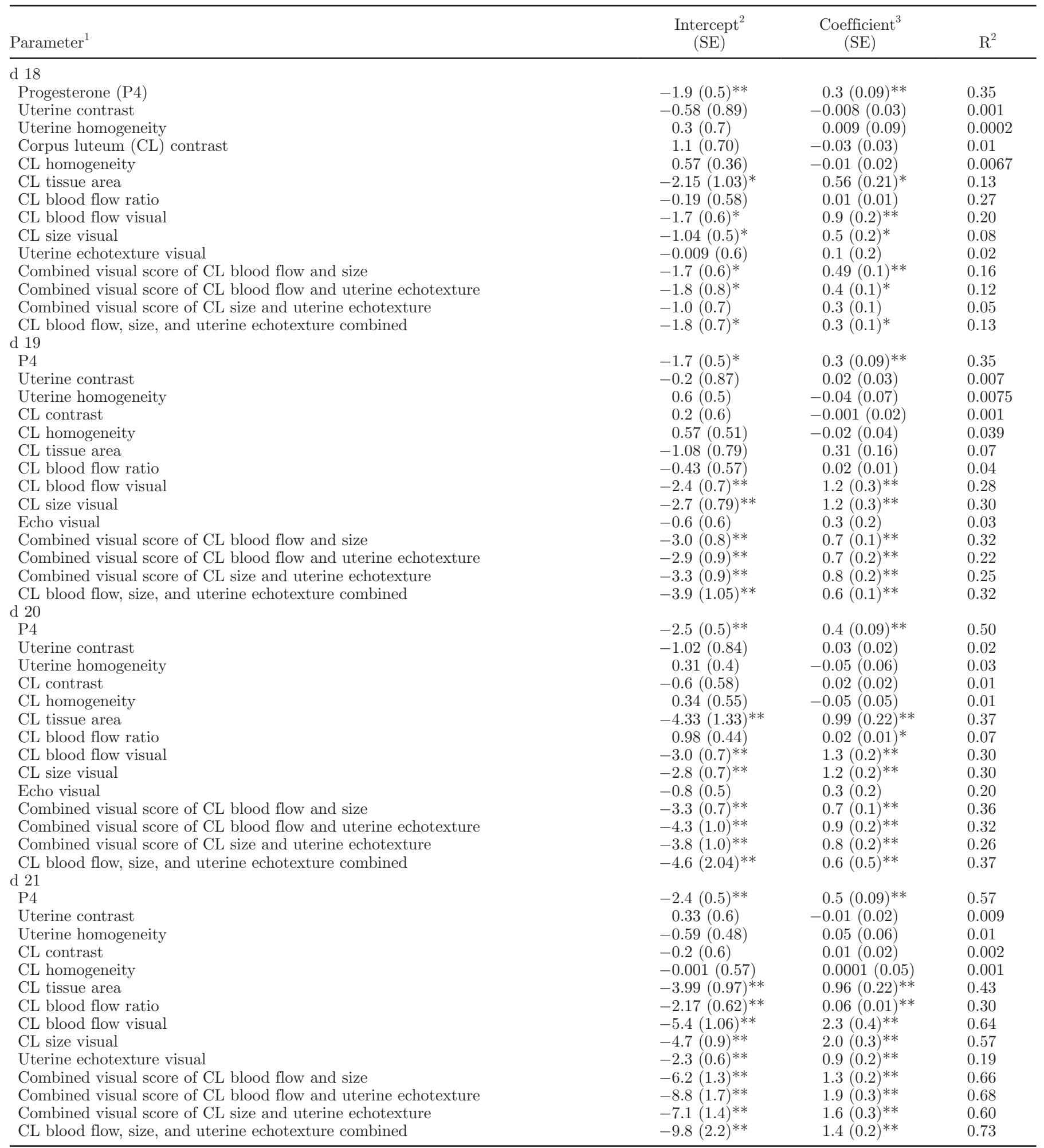

${ }^{1}$ Parameter $=$ end point for measurement of pregnancy status.

${ }^{2}$ Intercept $=$ intercept of the slope.

${ }^{3}$ Coefficient $=$ regression coefficient (slope) representing the rate of change in the variable of interest.

${ }^{* *} P<0.0001 ;{ }^{*} P<0.05$. 
Table 3. Best prediction equations for d 18, 19, 20, and 21 following AI for pregnancy status when progesterone (P4) was excluded and included $\mathrm{P} 4$ as a predictor

\begin{tabular}{|c|c|c|c|c|}
\hline Day $^{1}$ & $\begin{array}{l}\text { Intercept }^{2} \\
\quad(\mathrm{SE})\end{array}$ & $\begin{array}{l}\text { Coefficient }^{3} \\
\text { (SE) }\end{array}$ & Variable $^{4}$ & $\mathrm{R}^{2}$ \\
\hline \multicolumn{5}{|l|}{ P4 excluded } \\
\hline \multirow{2}{*}{18} & & $0.44(0.25)^{*}$ & CL tissue area & \\
\hline & & $0.29(0.15)^{*}$ & Combined visual score of CL blood flow, size, and uterine echotexture & \\
\hline 19 & $-3.64(1.3)^{*}$ & $0.5(1.8)^{* *}$ & Scores combined & 0.27 \\
\hline 20 & $-7.23(1.8)^{* *}$ & $0.06(0.03)$ & CL contrast & 0.43 \\
\hline \multirow[t]{3}{*}{21} & $-5.98(2.4)^{*}$ & $-0.08(0.05)$ & Uterine contrast & 0.72 \\
\hline & & $-0.1(0.09)$ & Uterine homogeneity & \\
\hline & & $1.3(0.2)^{* *}$ & Combined visual score of CL blood flow, size, and uterine echotexture & \\
\hline \multicolumn{5}{|c|}{ 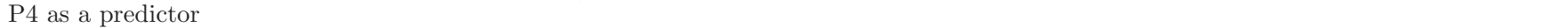 } \\
\hline \multirow[t]{3}{*}{18} & $-2.78(2.3)$ & $0.5(0.15)^{* *}$ & $\mathrm{P} 4$ & 0.44 \\
\hline & & $0.2(0.19)$ & Uterine homogeneity & \\
\hline & & $-0.07(0.05)$ & CL contrast & \\
\hline 20 & & $0.59(0.4)^{*}$ & CL tissue area & \\
\hline \multirow[t]{5}{*}{21} & $-6.9(2.9)^{*}$ & $0.34(0.16)^{*}$ & $\mathrm{P} 4$ & 0.75 \\
\hline & & $-0.08(0.05)$ & Uterine contrast & \\
\hline & & $-0.11(0.09)$ & Uterine homogeneity & \\
\hline & & $0.07(0.07)$ & CL contrast & \\
\hline & & $0.96(0.3)^{* *}$ & Combined visual scores of CL blood flow, size, and uterine echotexture & \\
\hline
\end{tabular}

${ }^{1}$ Day $=$ end point for measurement of pregnancy status.

${ }^{2}$ Intercept $=$ intercept of the slope.

${ }^{3}$ Coefficient $=$ regression coefficient (slope) representing the rate of change in the variable of interest.

${ }^{4}$ Variable $=$ variable chosen for prediction model.

${ }^{* *} P<0.0001 ;{ }^{*} P<0.05$.

2008, Diskin et al., 2011); it plays an integral part in modulation of the uterine environment and secretion of histotroph (Forde et al., 2011). In the current study, the correlation coefficient for the model in which P4 concentrations were used alone to predict pregnancy status from d 18 to 21 was low to moderate. A continuous improvement was noted in the correlation coefficient from d 18 to 21. The model using P4 on d 21 had the greatest correlation with pregnancy status outcome. However, this increased further when $\mathrm{P} 4$ was combined with some other US-derived marker. Although it has been demonstrated that concentrations of P4 and the rate at which the concentrations increase are related to embryo mortality during the early and midluteal phase after AI (Morris and Diskin, 2008), recent studies have shown that measuring $\mathrm{P} 4$ on $\mathrm{d} 7$ and 14 was not a good prediction of pregnancy loss in dairy cows (Kenyon et al., 2013). However, the fold change in P4 from $d 7$ to 14 was associated with pregnancy outcome on d 63 (Kenyon et al., 2013). It has been suggested that factors such as embryo mortality, irregular estrous cycles, and inaccurate estrous detection could influence P4 concentrations, which in turn would possibly bias a P4-based pregnancy diagnosis (Chebel et al., 2003). However, in the event of nonpregnancy, $\mathrm{P} 4$ may be an accurate measure of pregnancy diagnosis, as low concentrations would indicate a nonfunctional CL. Studies assessing the use of milk P4 as a pregnancy diagnosis have found that it can be applied for the detection of nonpregnant cows on d 19 (Oltenacu et al., 1990). In general, the diagnosis of pregnant cows is difficult due to variations in P4 concentration during early pregnancy (Mann and Lamming, 1999).

The premise behind using CL size as a possible indicator of pregnancy comes from the hypothesis that CL size may be a good marker of CL function, and thus P4 concentrations (Assey et al., 1993). In the current study, pregnant cows had greater CL tissue area compared with nonpregnant cows on all days of examination, and the frequency distribution for scores of CL size indicate that pregnant cows had more high scores (indicative of a larger CL) than nonpregnant cows on all days of examination. Correct diagnosis of the CL size using US is difficult (Hanzen et al., 2000). In nonpregnant cattle, upon initiation of luteolysis, $\mathrm{PGF}_{2 \alpha}$ from the uterus exerts a luteolytic effect on the CL and concentrations of P4 decrease (Ginther et al., 2010). A series of morphological changes also occur at this time, but they do 

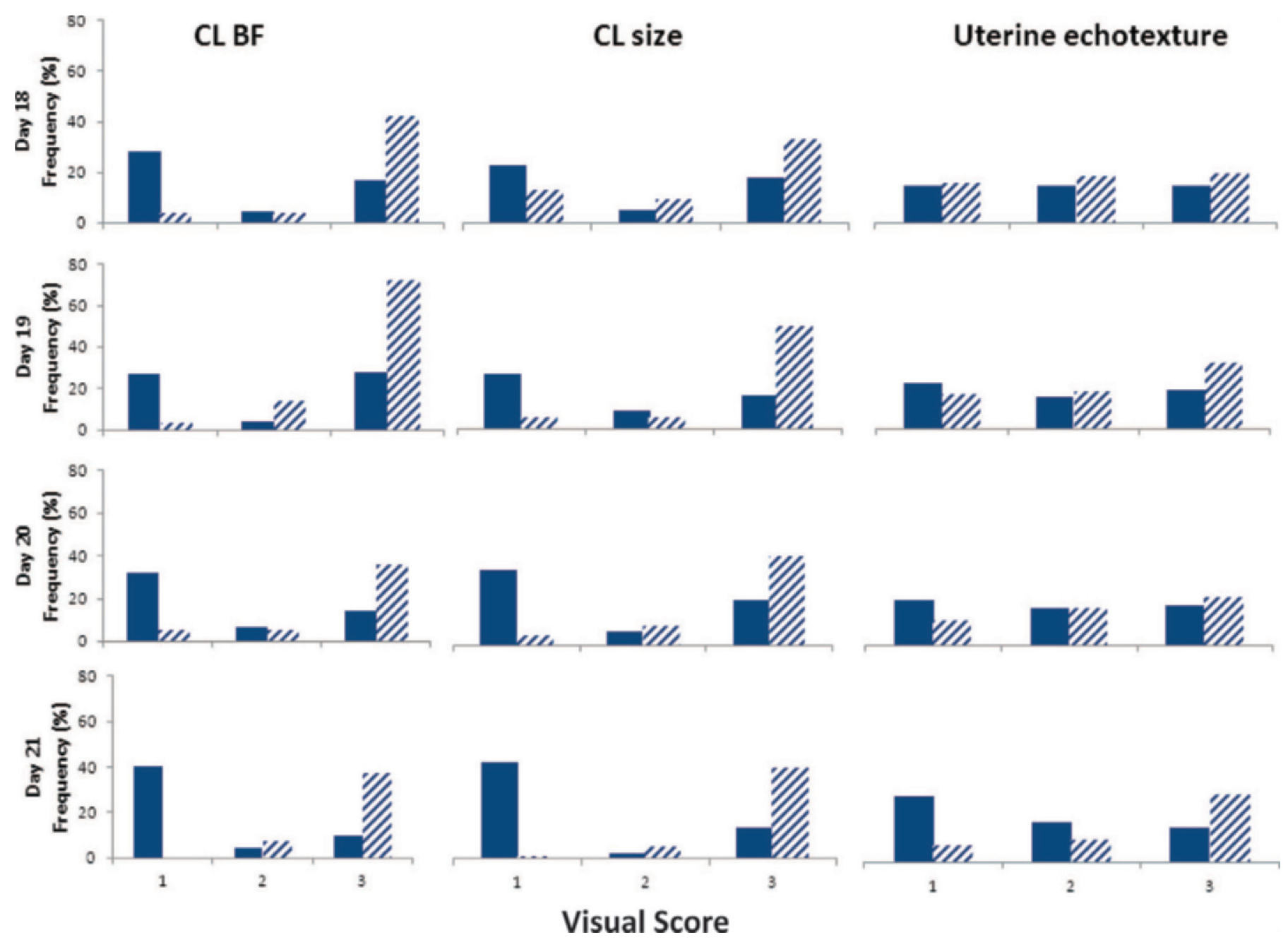

Figure 6. Frequency of visual scores of corpus luteum (CL) blood flow (BF; a), CL size (b), and uterine echotexture (c) in pregnant (n = 173; solid bars) and nonpregnant $(\mathrm{n}=171$; hashed bars) dairy cows from d 18 to 21 . Color version available in the online PDF.

not become evident until 24 to $36 \mathrm{~h}$ after initiation of $\mathrm{PGF}_{2 \alpha}$ pulses (Niswender et al., 2000). A difference in CL size between cows with circulating P4 concentrations of $<1 \mathrm{ng} / \mathrm{mL}$ and $>1 \mathrm{ng} / \mathrm{mL}$ has been reported (Sartori et al., 2004). However, a delay occurs from the time of functional to structural regression of the CL (Kastelic et al., 1990; Sartori et al., 2004; Ginther et al., 2012). Studies using either US or rectal palpation to predict CL function have concluded that CL size alone may not be a good indicator of its functional status (Hanzen et al., 2000; Bicalho et al., 2008). However, CL tissue area did appear in the best predictive model on $\mathrm{d}$ 18 and 20 and when CL size scores were removed, leaving only CL blood flow and uterine echotexture scores; NPV did not change but PPV decreased from 78 to $68 \%$. This indicates that by including CL size, more pregnant cows were diagnosed correctly.

Previous studies have demonstrated the correlation between the decrease in blood flow in the ovar- ian system and systemic P4 concentrations (Ford and Chenault, 1981; Wise et al., 1982). Corpus luteum blood flow during early pregnancy in dairy cows was higher in pregnant compared with nonpregnant cows on d 15 and 18 after estrus (Utt et al., 2009; Herzog et al., 2011). In pregnant cattle, a continued blood supply to the CL in association with conceptus derived interferon- $\tau$ blocking the increase in $\mathrm{PGF}_{2 \alpha}$ pulsatility has been observed (Beindorff et al., 2010). During early pregnancy, the vasculature of the CL tends to stabilize. This is evident by a reduction in angiogenic factors known to cause vascular instability and a continued expression of important vascular growth factors, such as vascular endothelial growth factor and fibroblastic growth factor (Berisha et al., 2000; Beindorff et al., 2010 ). In the absence of sufficient interferon- $\tau$ by the conceptus, the process of luteolysis begins (Ginther et al., 2010). Luteolysis is initiated by increased pulsatility of $\mathrm{PGF}_{2 \alpha}$ from the uterus and it has been shown 
Table 4. Pregnancy diagnosis sensitivities, specificities, and predictive probabilities for ultrasound examination based on a combined visual score for corpus luteum (CL) blood flow, CL size, and uterine echotexture (on a 3 to 9 scale where not-pregnant $=3-5$ and pregnant $=7-9)$ on d 18 to 21 in lactating dairy cows ${ }^{1}$

\begin{tabular}{|c|c|c|c|c|}
\hline \multirow[b]{2}{*}{ Parameter } & \multicolumn{4}{|c|}{ Day } \\
\hline & 18 & 19 & 20 & 21 \\
\hline Percent of total ${ }^{2}$ & 90 & 93 & 90 & 99 \\
\hline Total number of cows in the study & 80 & 80 & 90 & 94 \\
\hline Total cut-off ${ }^{3}$ & 72 & 74 & 81 & 93 \\
\hline Total pregnant & 38 & 42 & 38 & 42 \\
\hline Total nonpregnant & 34 & 32 & 43 & 51 \\
\hline \multicolumn{5}{|l|}{ Pregnancy state } \\
\hline $1-1^{4}$ & 30 & 39 & 34 & 41 \\
\hline $0-0^{5}$ & 19 & 22 & 29 & 40 \\
\hline $0-1^{6}$ & 8 & 3 & 4 & 1 \\
\hline $1-0^{7}$ & 15 & 10 & 14 & 11 \\
\hline Sensitivity (\%) & $78.9^{* * *}$ & $92.8^{* * *}$ & $89.4^{* * *}$ & $97.6^{* * *}$ \\
\hline $95 \%$ CI & $62.6-90.4$ & $80.5-98.5$ & $75.2-97$ & $87.4-99.9$ \\
\hline Specificity (\%) & $70.3^{*}$ & $88^{* * *}$ & $87.8^{* * *}$ & $97.5^{* * *}$ \\
\hline $95 \% \mathrm{CI}$ & $49.8-86.2$ & $68.7-97.4$ & $71.8-96.6$ & $87.1-99.9$ \\
\hline Positive predictive value (\%) & $66.6^{*}$ & $79.5^{* * *}$ & $70.8^{*}$ & $78.8^{* * *}$ \\
\hline $95 \% \mathrm{CI}$ & $51-80$ & $65.6-89.7$ & $55.9-83$ & $65.3-88.9$ \\
\hline Negative predictive value (\%) & $70.3^{*}$ & $88^{* * *}$ & $87.8^{* * *}$ & $97.5^{* * *}$ \\
\hline $95 \%$ CI & $49.8-86.2$ & $68.7-97.4$ & $71.8-96.6$ & $87.1-99.9$ \\
\hline
\end{tabular}

${ }^{1}$ The cut-off represents pregnant $(\mathrm{n}=160)$ and nonpregnant $(\mathrm{n}=160)$ cows

${ }^{2}$ Percent of total $=$ percentage of total animals in the study that qualified for the chosen cut-off.

${ }^{3}$ Total cut-off $=$ total number of animals included in the chosen cut-off.

${ }^{4}$ Diagnosed pregnant at ultrasound exam 1 and ultrasound exam 2 (d 30).

${ }^{5}$ Diagnosed not pregnant at ultrasound exam 1 and ultrasound exam 2 (d 30).

${ }^{6}$ Diagnosed not pregnant at ultrasound exam 1 and pregnant at ultrasound exam 2 (d 30).

${ }^{7}$ Diagnosed pregnant at ultrasound exam 1 and not pregnant at ultrasound exam 2 (d 30).

*** $P<0.00001 ; * P<0.05$.

that CL blood flow is one of the first components of the CL to react (Ginther et al., 2007; Shrestha et al., 2010).

Pregnant cows had higher values for CL blood flow area and blood flow ratio than their nonpregnant counterparts on d 20 and 21. However, the frequency of visual scores for CL blood flow shows pregnant cows with higher CL blood flow from d 18 to 21 compared with nonpregnant animals. In this instance, the scored method is likely to be more informative. The blood flow area and ratio were measured from 3 still images on a two-dimensional plane, whereas the score for CL blood flow was given while scanning through the CL several times during the US examination. The CL blood flow area only measured the area of the CL covered in pixels, not taking their brightness (i.e., intensity) into account. In comparison, the score for CL blood flow looked at both the amount of colored pixels and their intensity. Furthermore, in the current study, repeatability of CL blood flow area and ratio found these measures not to be as repeatable as previously reported (Herzog and Bollwein, 2007). Repeatability was weak to moderate, which may reflect a shortfall in the ability of pixel analysis to give a representative measure of CL blood flow. If this is the case, then perhaps alternative means of measuring CL blood flow using Doppler need to be addressed. For example, previous studies have described scoring the percentage of Doppler signals to the CL as a viable and valid method of measurement (Shrestha et al., 2010; Siddiqui et al., 2010). The results from the current study appear to be in agreement with previous studies where CL blood flow was visually assessed. When combined with the other visual scores, the score of CL blood flow appeared to be more predictive of pregnancy status than when measured by pixel analysis.

Characteristics of CL echotexture were not different between pregnant or nonpregnant cows on any day of US assessment. The predictive ability of CL echotexture characteristics was also very poor. Previous assessment of the CL echotexture reported an inability to distinguish between a functional and nonfunctional CL based on CL echotexture alone (Battocchio et al., 1999).

In the current study, the endometrium was evaluated by both echotexture analysis and visual score. The endometrium is where the greatest morphological changes occur during early pregnancy and approaching estrus in ruminant species (Reynolds and Redmer, 1992). No differences in the gray scale analysis for endometrial echotexture parameters were found between pregnant and nonpregnant cows in the present study. Both groups had almost identical profiles for contrast and homogeneity from d 18 to 21, and the frequency of scores 
Table 5. Frequency of score combinations in confirmed pregnant and nonpregnant lactating cows from d 18 to 21 following AI

\begin{tabular}{|c|c|c|c|c|c|}
\hline $\begin{array}{l}\text { Corpus luteum } \\
\text { (CL) size }\end{array}$ & Uterus $^{2}$ & CL blood flow ${ }^{3}$ & Frequency $^{4}$ & Percent $^{5}$ & Score $^{6}$ \\
\hline \multicolumn{6}{|c|}{ Confirmed pregnant } \\
\hline 1 & 1 & 1 & 6 & 3.21 & 3 \\
\hline 1 & 2 & 1 & 3 & 1.6 & 4 \\
\hline 2 & 1 & 1 & 1 & 0.53 & 4 \\
\hline 1 & 1 & 3 & 4 & 2.14 & 5 \\
\hline 1 & 2 & 2 & 1 & 0.53 & 5 \\
\hline 1 & 3 & 1 & 1 & 0.53 & 5 \\
\hline 1 & 2 & 3 & 1 & 0.53 & 6 \\
\hline 1 & 3 & 2 & 2 & 1.07 & 6 \\
\hline 2 & 1 & 3 & 5 & 2.67 & 6 \\
\hline 2 & 3 & 1 & 2 & 1.07 & 6 \\
\hline 3 & 2 & 1 & 3 & 1.6 & 6 \\
\hline 1 & 3 & 3 & 1 & 0.53 & 7 \\
\hline 2 & 2 & 3 & 6 & 3.21 & 7 \\
\hline 2 & 3 & 2 & 4 & 2.14 & 7 \\
\hline 3 & 1 & 3 & 1 & 0.53 & 7 \\
\hline 3 & 2 & 2 & 3 & 1.6 & 7 \\
\hline 3 & 3 & 1 & 24 & 13.37 & 7 \\
\hline 2 & 3 & 3 & 7 & 3.74 & 8 \\
\hline 3 & 2 & 3 & 10 & 5.35 & 8 \\
\hline 3 & 3 & 2 & 41 & 21.93 & 8 \\
\hline 3 & 3 & 3 & 47 & 25.13 & 9 \\
\hline \multicolumn{6}{|l|}{ Nonpregnant } \\
\hline 1 & 1 & 1 & 42 & 23.2 & 3 \\
\hline 1 & 1 & 2 & 25 & 13.81 & 4 \\
\hline 1 & 2 & 1 & 2 & 1.66 & 4 \\
\hline 2 & 1 & 1 & 3 & 2.21 & 4 \\
\hline 1 & 1 & 3 & 28 & 15.47 & 5 \\
\hline 1 & 2 & 2 & 1 & 0.55 & 5 \\
\hline 1 & 3 & 1 & 1 & 0.55 & 5 \\
\hline 2 & 1 & 2 & 3 & 1.66 & 5 \\
\hline 2 & 2 & 1 & 1 & 0.55 & 5 \\
\hline 3 & 1 & 1 & 2 & 1.1 & 5 \\
\hline 1 & 2 & 3 & 1 & 0.55 & 6 \\
\hline 2 & 1 & 3 & 2 & 1.1 & 6 \\
\hline 2 & 2 & 2 & 1 & 0.55 & 6 \\
\hline 2 & 3 & 1 & 3 & 1.66 & 6 \\
\hline 3 & 1 & 2 & 3 & 1.66 & 6 \\
\hline 3 & 2 & 1 & 3 & 1.66 & 6 \\
\hline 1 & 3 & 3 & 1 & 0.55 & 7 \\
\hline 2 & 2 & 3 & 1 & 0.55 & 7 \\
\hline 3 & 1 & 3 & 2 & 1.1 & 7 \\
\hline 3 & 2 & 2 & 2 & 1.1 & 7 \\
\hline 3 & 3 & 1 & 10 & 5.52 & 7 \\
\hline 2 & 3 & 3 & 2 & 1.1 & 8 \\
\hline 3 & 2 & 3 & 3 & 1.66 & 8 \\
\hline 3 & 3 & 2 & 17 & 9.39 & 8 \\
\hline 3 & 3 & 3 & 12 & 6.63 & 9 \\
\hline
\end{tabular}

${ }^{1}$ CL size score.

${ }^{2}$ Uterine echotexture score

${ }^{3}$ CL blood flow score.

${ }^{4}$ Frequency of score combination.

${ }^{5}$ Percent of population.

${ }^{6}$ Score when combined.

for uterine echotexture were similar between pregnant and nonpregnant cows on all days of US examination. Pregnant cows did appear to have a higher frequency of high scores on d 21 compared with nonpregnant cows. Higher scores for uterine echotexture represent darker nonechogenic regions along the endometrium. Both visual scores and echotexture analyses were looking for changes in the texture of the endometrium. Several possible reasons exist as to why a difference was detected on d 21 using the score method. As with CL blood flow analysis, it is possible that 3 still images of each uterine horn are not representative of a live examination where the uterus is being scanned sequentially several times before images were captured. Scoring the echotexture of 
Table 6. Correlation coefficients and significance levels between progesterone and visual scores for corpus luteum (CL) blood flow, CL size, and uterine echotexture from d 18 to 21 in both pregnant and nonpregnant cows

\begin{tabular}{lcccc}
\hline Item & Progesterone & $\begin{array}{c}\text { CL blood flow } \\
\text { visual score }\end{array}$ & $\begin{array}{c}\text { CL size } \\
\text { visual score }\end{array}$ & $\begin{array}{c}\text { Uterine } \\
\text { echotexture } \\
\text { visual score }\end{array}$ \\
\hline Progesterone & 1.000 & $0.64^{* *}$ & $0.6^{* *}$ & $0.17^{*}$ \\
CL blood flow visual score & $0.62^{* *}$ & 1.0000 & $0.78^{* *}$ & $0.13^{*}$ \\
CL size visual score & $0.6^{* *}$ & $0.78^{* *}$ & 1.0000 & $0.16^{*}$ \\
Uterine echotexture visual score & $0.17^{*}$ & $0.13^{*}$ & $0.16^{*}$ & 1.0000 \\
\hline$* * P<0.0001 ;{ }^{*} P<0.05$ & &
\end{tabular}

** $P<0.0001 ; * P<0.05$.

the uterus has been reported in previous studies where uterine echotexture scores were higher in nonpregnant compared with pregnant cows on d 18 (Silva and Ginther, 2010). The opposite was observed in the current study, but this could be related to scoring definitions used. This could be a result of differences in definitions used or perhaps differences in the appearance of the uterus resulting from the use of a standard, lowfrequency machine. As with CL size, the removal of uterine echotexture scores from the diagnosis resulted in a reduction of the PPV. Uterine echotexture alone may not be hugely predictive of pregnancy, but when included as part of a whole reproductive tract exam it could prove more valuable.

The increase in echotexture scores on d 21 may be representative of the increase in secretory glands and microvasculature known to be associated with endometrial development during implantation (Reynolds and Redmer, 1992; Gray et al., 2001). In the nonpregnant animal, oxytocin-dependent pulses of $\mathrm{PGF}_{2 \alpha}$ are released from the endometrium, causing functional and structural regression of the CL. In these animals, no need for increased glandular secretion exists, although increased mucous secretion has been noted. This may lead to difficulty in distinguishing endometrial echotexture related to implantation and that associated with preparation for estrus. Previous US studies have reported cyclic changes in uterine echotexture pattern using second-order gray level statistics (Schmauder et al., 2008). However, no correlation was reported between P4 and gray scale values (Schmauder et al., 2008).

Based on results from the logistic regression analysis, it appeared that the combined scored data contributed most to the best predictive model for pregnancy diagnosis. When included, P4 replaced uterine echotexture scores on $\mathrm{d} 21$. This increased the predictive value slightly. Furthermore, P4 has not been found to be a valuable marker of pregnancy status owing to variable $\mathrm{P} 4$ concentrations during early pregnancy in cows (Mann and Lamming, 1999).

Pregnancy diagnosis based on the combined scores indicated that PPV and NPV on d 20 and 21 were between 70 and $98 \%$. Following the analysis of several possible cut-off values that would be representative of pregnant and nonpregnant cows, a cut-off that represented $93 \%$ of the population appeared to be the most predictive cut-off while including most of the population. This means that scores from approximately $7 \%$ of the population were deemed questionable and not included. In a commercial situation, such animals could then be scanned on d 60 alongside cows receiving a second confirmatory scan at d 60. Recent studies on cows and heifers found a PPV and NPV of 65.1 and 98.5, respectively, on d 20 when analyzing CL blood flow alone (Siqueira et al., 2013). On d 21, assessment of CL blood flow alone for diagnosis of pregnancy reported PPV and NPV to be 68.4 and $81.5 \%$, respectively (Utt et al., 2009). The assessment of CL blood flow alone would possibly be more convenient and slightly less time consuming. However, results from the current study indicate that removal of either CL size score of uterine echotexture score reduced diagnostic accuracy particularly for the diagnosis of pregnant cows. Whereas the results from this and other similar studies are positive, further US studies in large groups of cows are required to validate if assessment of CL blood flow alone is a sufficient for US diagnosis of pregnancy diagnosis on d 21 following AI.

In the current study, the percentage of correct positive (sensitivity) and correct negative (specificity) diagnoses made were 97.6 and $97.5 \%$, respectively. In comparison, the pregnancy-associated glycoproteins test has been shown to have a sensitivity and specificity of 93.5 and $96.3 \%$, respectively, on d 25 (Silva et al., 2007). Few US studies for pregnancy diagnosis have tested from d 18 to 21. Previous US examinations of the reproductive tract between d 21 and 35 after AI have reported PPV ranging from 70 to $90 \%$ and NPV ranging from 63 to 100\% (Pieterse et al., 1990; Badtram et al., 1991; Nation et al., 2003; Romano et al., 2006).

The level of false positives was between 12 and 20\%, which could have been due to embryonic mortality. On d 21, approximately $38 \%$ of cows had P4 concentrations $<1 \mathrm{ng} / \mathrm{mL}$, which might indicate either absence of an embryo or, if present, early embryo loss; whereas $17 \%$ of cows had $\mathrm{P} 4>1 \mathrm{ng} / \mathrm{mL}$ on $\mathrm{d} 21$, which may 
indicate late embryo loss after the confirmation of nonpregnancy on d 30 (Utt et al., 2009). These figures are in agreement with the recent reports of embryo loss in moderate-yielding dairy cows. With a fertilization rate of $90 \%$, embryonic mortality between conception and d 24 is approximately 40\%; approximately 70 to $80 \%$ of this loss occurs between d 8 and 16 (Diskin and Morris, 2008; Diskin et al., 2011). Late embryonic mortality after d 24 is lower at approximately $10 \%$ in moderate- to high-yielding cows on pasture (Silke et al., 2002). Recent evidence would suggest that higher rates of late embryo or early fetal loss are occurring in high-yielding and intensively managed systems (Bartolome et al., 2005, Diskin et al., 2011). The occurrence of embryo mortality following pregnancy diagnosis is thought to be a major factor influencing its economic value (Giordano et al., 2013).

\section{CONCLUSIONS}

The logistic regression equation most likely to provide a correct pregnancy diagnosis included the visual scores for CL blood flow, CL size, and uterine echotexture on d 21 after AI in lactating dairy cows. In support of this finding, the diagnostic accuracy for visual scores of CL blood flow, CL size, and uterine echotexture was also highest on d 21. The diagnostic accuracy of these scores suggests a higher negative predictive value $(97 \%)$ than positive predictive value $(68 \%)$. Therefore, if US were found to be useful, the main focus of a US examination at this time would be to identify nonpregnant cows that are eligible for resynchronization.

\section{REFERENCES}

Assey, R. J., B. Purwantara, T. Greve, P. Hyttel, and M. H. Schmidt. 1993. Corpus luteum size and plasma progesterone levels in cattle after cloprostenol-induced luteolysis. Theriogenology 39:13211330.

Badtram, G. A., J. D. Gaines, C. B. Thomas, and W. T. K. Bosu. 1991. Factors influencing the accuracy of early pregnancy detection in cattle by real-time ultrasound scanning of the uterus. Theriogenology 35:1153-1167.

Bartolome, J. A., F. T. Silvestre, S. Kamimura, A. C. M. Arteche, P. Melendez, D. Kelbert, J. McHale, K. Swift, L. F. Archbald, and W. W. Thatcher. 2005. Resynchronization of ovulation and timed insemination in lactating dairy cows: I: Use of the Ovsynch and Heatsynch protocols after non-pregnancy diagnosis by ultrasonography. Theriogenology 63:1617-1627.

Battocchio, M., G. Gabai, A. Mollo, M. C. Veronesi, F. Soldano, G. Bono, and F. Cairoli. 1999. Agreement between ultrasonographic classification of the CL and plasma progesterone concentration in dairy cows. Theriogenology 51:1059-1069.

Beindorff, N., K. Nagai, K. Shirasuna, K. Herzog, K. Hoeffmann, M. Sasaki, H. Bollwein, and A. Miyamoto. 2010. Vascular changes in the corpus luteum during early pregnancy in the cow. J. Reprod. Dev. 56:263-270.

Berisha, B., D. Schams, M. Kosmann, W. Amselgruber, and R. Einspanier. 2000. Expression and localisation of vascular endothelial growth factor and basic fibroblast growth factor during the final growth of bovine ovarian follicles. J. Endocrinol. 167:371-382.

Bicalho, R. C., K. N. Galvão, C. L. Guard, and J. E. P. Santos. 2008. Optimizing the accuracy of detecting a functional corpus luteum in dairy cows. Theriogenology 70:199-207.

Butler, W. R. 2003. Energy balance relationships with follicular development, ovulation and fertility in postpartum dairy cows. Livest. Prod. Sci. 83:211-218.

Chebel, R. C., J. E. P. Santos, R. L. A. Cerri, K. N. Galvão, S. O Juchem, and W. W. Thatcher. 2003. Effect of resynchronization with GnRH on day 21 after artificial insemination on pregnancy rate and pregnancy loss in lactating dairy cows. Theriogenology 60:1389-1399.

Dewey, S. T., L. G. D. Mendonça, G. Lopes, F. A. Rivera, F. Guagnini, R. C. Chebel, and T. R. Bilby. 2010. Resynchronization strategies to improve fertility in lactating dairy cows utilizing a presynchronization injection of GnRH or supplemental progesterone: I. Pregnancy rates and ovarian responses. J. Dairy Sci. 93:4086-4095.

Dillon, P., D. P. Berry, R. D. Evans, F. Buckley, and B. Horan. 2006. Consequences of genetic selection for increased milk production in European seasonal pasture based systems of milk production. Livest. Sci. 99:141-158.

Diskin, M. G., and D. G. Morris. 2008. Embryonic and early foetal losses in cattle and other ruminants. Reprod. Domest. Anim. 43:260-267.

Diskin, M. G., M. H. Parr, and D. G. Morris. 2011. Embryo death in cattle: An update. Reprod. Fertil. Dev. 24:244-251.

Dobson, H., S. L. Walker, M. J. Morris, J. E. Routly, and R. F. Smith. 2008. Why is it getting more difficult of sucessfully artifically inseminate dairy cows? Animal 2:1104-1111.

Dunne, L. D., M. G. Diskin, and J. M. Sreenan. 2000. Embryo and foetal loss in beef heifers between day 14 of gestation and full term. Anim. Reprod. Sci. 58:39-44.

Ford, S. P., and J. R. Chenault. 1981. Blood flow to the corpus luteum-bearing ovary and ipsilateral uterine horn of cows during the oestrous cycle and early pregnancy. J. Reprod. Fertil. 62:555-562.

Forde, N., M. E. Beltman, G. B. Duffy, P. Duffy, and J. P. Mehta., PO'Gaora, J. F., P. Roche, Lonergan, and M. A. Crowe. 2011. Changes in the endometrial transcriptome during the bovine estrous cycle: Effect of low circulating progesterone and consequences for conceptus elongation. Biol. Reprod. 84:266-278.

Fricke, P. M. 2002. Scanning the future-Ultrasonography as a reproductive management tool for dairy cattle. J. Dairy Sci. 85:19181926.

Gajewski, Z., R. Thun, R. Faundez, and Z. Boryczko. 1999. Uterine motility in the cow during puerperium. Reprod. Domest. Anim. $34: 185-191$

Ginther, O. J., F. A. Khan, M. A. Hannan, M. B. Rodriguez, G. Pugliesi, and M. A. Beg. 2012. Role of LH in luteolysis and growth of the ovulatory follicle and estradiol regulation of LH secretion in heifers. Theriogenology 77:1442-1452.

Ginther, O. J., H. K. Shrestha, M. J. Fuenzalida, A. K. M. Shahiduzzaman, M. A. Hannan, and M. A. Beg. 2010. Intrapulse temporality between pulses of a metabolite of prostaglandin $\mathrm{F}_{2 \alpha}$ and circulating concentrations of progesterone before, during, and after spontaneous luteolysis in heifers. Theriogenology 74:1179-1186.

Ginther, O. J., L. A. Silva, R. R. Araujo, and M. A. Beg. 2007. Temporal associations among pulses of 13,14-Dihydro-15-keto-PGF2alpha, luteal blood flow, and luteolysis in cattle. Biol. Reprod. $76: 506-513$.

Giordano, J. O., P. M. Fricke, and V. E. Cabrera. 2013. Economics of resynchronization strategies including chemical tests to identify nonpregnant cows. J. Dairy Sci. 96:949-961.

Gray, C. A., F. F. Bartol, B. J. Tarleton, A. A. Wiley, G. A. Johnson, F. W. Bazer, and T. E. Spencer. 2001. Developmental biology of uterine glands. Biol. Reprod. 65:1311-1323.

Green, J. A., T. E. Parks, M. P. Avalle, B. P. Telugu, A. L. McLain, A. J. Peterson, W. McMillan, N. Mathialagan, R. R. Hook, S. Xie, and R. M. Roberts. 2005. The establishment of an ELISA for the detection of pregnancy-associated glycoproteins (PAGs) in the serum of pregnant cows and heifers. Theriogenology 63:1481-1503. 
Green, J. C., D. H. Volkmann, S. E. Prook, M. F. McGrath, M. Ehrhardt, A. E. Moseley, and M. C. Lucy. 2009. Technical note: A rapid enzyme-linked immunosorbent assay blood test for pregnancy in dairy and beef cattle. J. Dairy Sci. 3819-3824.

Hanzen, C., M. Pieterse, O. Scenczi, and M. Drost. 2000. Relative accuracy of the identification of ovarian structures in the cow by ultrasonography and palpation per rectum. Vet. J. 159:161-170.

Herzog, K., and H. Bollwein. 2007. Application of Doppler ultrasonography in cattle reproduction. Reprod. Domest. Anim. 42(Suppl 2):51-58,

Herzog, K., C. Voss, J. P. Kastelic, N. Beindorff, V. Paul, H. Niemann, and H. Bollwein. 2011. Luteal blood flow increases during the first three weeks of pregnancy in lactating dairy cows. Theriogenology $75: 549-554$.

Kastelic, J. P., D. R. Bergfelt, and O. J. Ginther. 1990. Relationship between ultrasonic assessment of the corpus luteum and plasma progesterone concentration in heifers. Theriogenology 33:12691278.

Kastelic, J. P., D. R. Bergfelt, and O. J. Ginther. 1991. Ultrasonic detection of the conceptus and characterization of intrauterine fluid on days 10 to 22 in heifers. Theriogenology 35:569-581.

Kastelic, J. P., S. Curran, and O. J. Ginther. 1989. Accuracy of ultrasonography for pregnancy diagnosis on days 10 to 22 in heifers. Theriogenology 31:813-820.

Kastelic, J. P., S. Curran, R. A. Pierson, and O. J. Ginther. 1988. Ultrasonic evaluation of the bovine conceptus. Theriogenology 29:39-54.

Kenyon, A. G., L. G. D. Mendonça, G. Lopes Jr., J. R. Lima, J. E. P. Santos, and R. C. Chebel. 2013. Minimal progesterone concentration required for embryo survival after embryo transfer in lactating Holstein cows. Anim. Reprod. Sci. 136:223-230.

Lopez, H., L. D. Satter, and M. C. Wiltbank. 2004. Relationship between level of milk production and estrous behavior of lactating dairy cows. Anim. Reprod. Sci. 81:209-223.

López-Gatius, F., and I. García-Ispierto. 2010. Ultrasound and endocrine findings that help to assess the risk of late embryo/early foetal loss by non-infectious cause in dairy cattle. Reprod. Domest. Anim. 45:15-24.

Lowman, B. G., N. A. Scott, and S. H. Somerville. 1976. Condition scoring of cattle. East of Scotland College of Agriculture Bulletin No. 6 (rev.ed.), Edinburgh, UK.

Mann, G. E., and G. E. Lamming. 1999. The influence of progesterone during early pregnancy in cattle. Reprod. Domest. Anim. 34:269-274.

Mee, J. F. 2004. Temporal trends in reproductive performance in Irish dairy herds and associated risk factors. Ir. Vet. J. 57:158-166.

Morris, D., and M. Diskin. 2008. Effect of progesterone on embryo survival. Animal 2:1112-1119.

Nation, D. P., J. Malmo, G. M. Davis, and K. L. Macmillan. 2003. Accuracy of bovine pregnancy detection using transrectal ultrasonography at 28 to 35 days after insemination. Aust. Vet. J. 81:63-65.

Niswender, G. D., J. L. Juengel, P. J. Silva, M. K. Rollyson, and E. W. McIntush. 2000. Mechanisms controlling the function and life span of the corpus luteum. Physiol. Rev. 80:1-29.

Oltenacu, P. A., J. D. Ferguson, and A. J. Lednor. 1990. Economic evaluation of pregnancy diagnosis in dairy cattle: A decision analysis approach. J. Dairy Sci. 73:2826-2831.

Pierson, R. A., and O. J. Ginther. 1984. Ultrasonography for detection of pregnancy and study of embryonic development in heifers. Theriogenology 22:225-233.

Pierson, R. A., and O. J. Ginther. 1987. Ultrasonographic appearance of the bovine uterus during the estrous cycle. J. Am. Vet. Med. Assoc. 190:995-1001.

Pieterse, M. C., O. Szenci, A. H. Willemse, C. S. A. Bajcsy, S. J. Dieleman, and M. A. M. Taverne. 1990. Early pregnancy diagnosis in cattle by means of linear-array real-time ultrasound scanning of the uterus and a qualitative and quantitative milk progesterone test. Theriogenology 33:697-707.

Raeth, U., D. Schlaps, B. Limberg, I. Zuna, A. Lorenz, G. Van Kaick, W. J. Lorenz, and B. Kommerell. 1985. Diagnostic accuracy of computerized B-scan texture analysis and conventional ultrasonog- raphy in diffuse parenchymal and malignant liver disease. J. Clin. Ultrasound 13:87-99.

Reynolds, L. P., and D. A. Redmer. 1992. Growth and microvascular development of the uterus during early pregnancy in ewes. Biol. Reprod. 47:698-708.

Romano, J. E., J. A. Thompson, D. W. Forrest, M. E. Westhusin, M. A. Tomaszweski, and D. C. Kraemer. 2006. Early pregnancy diagnosis by transrectal ultrasonography in dairy cattle. Theriogenology 66:1034-1041.

Sartori, R., M. R. Bastos, and M. C. Wiltbank. 2010. Factors affecting fertilisation and early embryo quality in single- and superovulated dairy cattle. Reprod. Fertil. Dev. 22:151-158.

Sartori, R., J. M. Haughian, R. D. Shaver, G. J. M. Rosa, and M. C. Wiltbank. 2004. Comparison of ovarian function and circulating steroids in estrous cycles of Holstein heifers and lactating cows. J. Dairy Sci. 87:905-920.

Schmauder, S., F. Weber, E. Kiossis, and H. Bollwein. 2008. Cyclic changes in endometrial echotexture of cows using a computerassisted program for the analysis of first- and second-order grey level statistics of B-Mode ultrasound images. Anim. Reprod. Sci. 106:153-161.

Shrestha, H. K., M. A. Beg, S. Imam, and O. J. Ginther. 2010. Luteal blood flow and concentrations of circulating progesterone and other hormones associated with a simulated pulse of 13,14-dihydro15-keto-prostaglandin F2 $\alpha$ in heifers. Reproduction 139:673-683.

Siddiqui, M. A. R., J. C. Ferreira, E. L. Gastal, M. A. Beg, D. A Cooper, and O. J. Ginther. 2010. Temporal relationships of the LH surge and ovulation to echotexture and power Doppler signals of blood flow in the wall of the preovulatory follicle in heifers. Reprod. Fertil. Dev. 22:1110-1117.

Silke, V., M. G. Diskin, D. A. Kenny, M. P. Boland, P. Dillon, J. F Mee, and J. M. Sreenan. 2002. Extent, pattern and factors associated with late embryonic loss in dairy cows. Anim. Reprod. Sci. $71: 1-12$.

Silva, E., R. A. Sterry, D. Kolb, N. Mathialagan, M. F. McGrath, J. M. Ballam, and P. M. Fricke. 2007. Accuracy of a pregnancy associated glycoprotein ELISA to determine pregnancy status of lactating dairy cows twenty seven days after timed artificial insemination. J. Dairy Sci. 92:3819-3824.

Silva, L. A., and O. J. Ginther. 2010. Local effect of the conceptus on uterine vascular perfusion during early pregnancy in heifers. Reproduction 139:453-463.

Siqueira, L. G. B., V. S. Areas, A. M. Ghetti, J. F. Fonseca, M. P. Palhao, C. A. C. Fernandes, and J. H. M. Viana. 2013. Color Doppler flow imaging for the early detection of nonpregnant cattle at 20 days after timed artificial insemination. J. Dairy Sci. 96:6461-6473

Spencer, T. E., G. A. Johnson, F. W. Bazer, R. C. Burghardt, and M. Palmarini. 2007. Pregnancy recognition and conceptus implantation in domestic ruminants: Roles of progesterone, interferons and endogenous retroviruses. Reprod. Fertil. Dev. 19:65-78.

Stevenson, J. S., J. A. Cartmill, B. A. Hensley, and S. Z. El-Zarkouny. 2003. Conception rates of dairy cows following early not-pregnant diagnosis by ultrasonography and subsequent treatments with shortened Ovsynch protocol. Theriogenology 60:475-483.

Strzelecki, M., P. Szczypinski, A. Materka, and A. Klepaczko. 2013. A software tool for automatic classification and segmentation of 2D/3D medical images. Nucl. Instrum. Methods Phys. Res. A 702:137-140.

Szczypiński, P. M., M. Strzelecki, A. Materka, and A. Klepaczko. 2009. MaZda-A software package for image texture analysis. Comput. Methods Programs Biomed. 94:66-76.

Utt, M. D., G. L. Johnson Iii, and W. E. Beal. 2009. The evaluation of corpus luteum blood flow using color-flow Doppler ultrasound for early pregnancy diagnosis in bovine embryo recipients. Theriogenology 71:707-715.

Wise, T. H., D. Caton, W. W. Thatcher, D. H. Barron, and M. J. Fields. 1982. Ovarian function during the estrous cycle of the cow: Ovarian blood flow and progesterone release rate. J. Anim. Sci. 55:627-637. 